\title{
Impact of particle size and morphology of cobalt oxide on the thermal response to methane examined by thermal analysis
}

\author{
Olena Yurchenko ${ }^{1,2}$, Hans-Fridtjof Pernau ${ }^{1}$, Laura Engel ${ }^{1}$, Benedikt Bierer ${ }^{1}$, Martin Jägle ${ }^{1}$, and \\ Jürgen Wöllenstein ${ }^{1,2}$ \\ ${ }^{1}$ Fraunhofer Institute for Physical Measurement Techniques IPM, \\ Georges-Koehler-Allee 301, 79110 Freiburg, Germany \\ ${ }^{2}$ Department of Microsystems Engineering - IMTEK, University of Freiburg, \\ Georges-Koehler-Allee 102, 79110 Freiburg, Germany
}

Correspondence: Olena Yurchenko (olena.yurchenko@ipm.fraunhofer.de)

Received: 28 October 2020 - Revised: 15 January 2021 - Accepted: 20 January 2021 - Published: 24 February 2021

\begin{abstract}
Differential thermal analysis (DTA) was used to examine the effect of the particle size and morphology of cobalt (III/IV) oxide $\left(\mathrm{Co}_{3} \mathrm{O}_{4}\right)$ on its thermal response under exposure to methane $(1 \mathrm{vol} \%$ in dry synthetic air), which is a relevant gas for the detection of combustible gases. The DTA response results from the catalytic oxidation of methane, and its characteristics should correlate with the pellistor response. $\mathrm{Co}_{3} \mathrm{O}_{4}$ samples differing in particle size and morphology were produced by ball milling (top-down technique) or were synthesized from precursor molecules by precipitation (bottom-up technique). The investigations carried out in dry air and a temperature range between 250 and $450^{\circ} \mathrm{C}$ reveal that both particle size and particle shape have a considerable effect on thermal response, since the resulting layer structures and the associated surface area available for gas interaction differ. The $\mathrm{Co}_{3} \mathrm{O}_{4}$ catalyst, with small particles and an irregular shape, exhibits significantly higher response than milled $\mathrm{Co}_{3} \mathrm{O}_{4}$ samples. Comparison of DTA with the mass spectroscopy signal of $\mathrm{CO}_{2}$ evolved by the reaction verified a certain analogy between DTA measurements and the response produced by a pellistor.
\end{abstract}

\section{Introduction}

In the field of safety technology, catalytic sensors, so-called pellistors, are commonly used for the detection of flammable gases such as hydrocarbons. A pellistor typically consists of two sensor elements. One sensor element, called the "detector", contains the active catalyst and is designed to respond to the target gas. The other sensor element is the "compensator", manufactured without a catalyst, and only responds to changes in environmental conditions, thus providing an inherent temperature compensation (White, 2014). In the presence of a combustible gas, heat is generated due to the catalytic oxidation of gas on the catalytic layer of the detector. This generates an electrical signal, which corresponds to gas concentration in the environment.
Currently, commercially available pellistors typically operate at high temperatures $\left(>450^{\circ} \mathrm{C}\right)$ to ensure the accurate detection of methane, which is the most inert combustible gas (Trautweiler et al., 2012). However, high operating temperatures entail some disadvantages, such as high power consumption and reduced catalyst stability. Reducing the operating temperature should contribute to a decrease in the power consumption and an increase in the sensor's operating time due to a slower aging of the catalyst. Especially for the detection of methane, catalysts of high activity and stability are required for the reduction in the operating temperature.

The choice of suitable catalysts for the targeted gas sensor application is not easy when considered from different points of view. First, the catalytic material used for sensors is a complex system consisting of catalysts and various additives that enable the integration into the sensor and generate the mechanical stability of the catalytic layer. Additives can 
affect the catalyst activity and stability, and their effect is difficult to identify during the characterization of the gas sensor. Second, the response detected by a sensor is a complex reaction as well, as it is determined by the whole sensor system. Third, the preparation process of individual sensors is quite extensive. This additionally limits a specified evaluation of the effects of physical properties such as the surface area or particle size distribution.

To overcome these limitations existing in investigations of pellistor gas sensors, thermal analysis methods, including differential scanning calorimetry (DSC) or differential thermal analysis (DTA), can be used to perform the preselection of the catalysts (Le Parlouër, 2013; Janssen, 1989; Borchardt and Daniels, 1957). DSC is a well-known technique in catalyst research and widely used for investigation of catalytic reactions (Hakvoort and Xiaoding, 1991; Loskyll et al., 2012; Hakvoort, 1996). In DSC, the heat flux difference to/from the sample, compared to the reference, is recorded versus time, while both are subjected to a controlled temperature program. However, DTA should be more appropriate for the investigation of catalysts for gas sensor purpose, since the temperature difference $\Delta T$ between the sample and reference is measured when both are subjected to equal heat fluxes in a controlled atmosphere (Beecroft et al., 1975). The DTA method, therefore, uses a functional principle that is comparable to that used for pellistor measurements. The combination of thermal analysis methods with a mass spectrometry (MS) technique for the analysis of the evolving gases can provide additional complementary information that is useful for investigations (Hakvoort, 1996).

In the present work, we report on the use of a differential thermal analysis system that, in combination with a mass spectrometer, is used for a catalyst examination to define the influence of particle size and morphology on the thermal response. Some kinds of metal oxides, like $\mathrm{CuO}, \mathrm{Co}_{3} \mathrm{O}_{4}$, $\mathrm{MnO}_{x}$ and $\mathrm{CeO}_{2}$ (Chen et al., 2015), can act as catalyst for the oxidation of flammable gases. Thus, spinel $\mathrm{Co}_{3} \mathrm{O}_{4}$, which is reported to be a promising catalyst for methane combustion (Pu et al., 2017), was used as noble metal-free catalytic material for the investigations. The size of the catalytic particles has a significant, but sometimes opposite, effect on the catalytic oxidation of methane. Investigations on noble metal catalysts $\mathrm{Pt} / \mathrm{Al}_{2} \mathrm{O}_{3}$ (Stakheev et al., 2013) and $\mathrm{Au} / \mathrm{Al}_{2} \mathrm{O}_{3}$ (Grisel et al., 2000) have shown that the reduction in Au particle size, from 44 to $3-5 \mathrm{~nm}$, leads to a rise in the catalytic activity, whereas no significant effect could be observed for $\mathrm{Pt} / \mathrm{Al}_{2} \mathrm{O}_{3}$ catalyst for Pt particles in the range between 2 and $14 \mathrm{~nm}$. In turn, the intrinsic catalytic activity of a $\mathrm{Pd} / \mathrm{Al}_{2} \mathrm{O}_{3}$ catalyst considerably increases when the Pd particle size grows from 1 to $20 \mathrm{~nm}$ (Stakheev et al., 2013). Also, for $\mathrm{Co}_{3} \mathrm{O}_{4}$ catalysts, the influence of morphology and crystallite size on catalytic behavior in methane combustion was reported (Pu et al., 2017; Chen et al., 2016).

The effect of particle size on methane oxidation was systematically investigated at different operating temperatures using $\mathrm{Co}_{3} \mathrm{O}_{4}$ catalyst materials that were produced with different milling times (top-down technique) to achieve different particle sizes. To include the effect of morphology in the investigations, intrinsically nano-sized $\mathrm{Co}_{3} \mathrm{O}_{4}$ material (bottom-up technique) was synthesized. The thermal response of the methane oxidation was observed using DTA and compared to the mass spectrometer response, which directly reflects the methane conversion.

\section{Experiment}

The commercially available STA-QMS (simultaneous thermal analyzer and quadrupole mass spectrometer; NETZSCH-Gerätebau GmbH; STA 409 CD-QMS 403/5 SKIMMER), equipped with a DTA sample carrier, was adapted for the investigation of catalytic activity at dry conditions. The integrated quadrupole mass spectrometer was used to analyze $\mathrm{CO}_{2}$ species in exhaust gas that evolved during the catalytic reaction. Therefore, the characteristic mass number of $\mathrm{CO}_{2}(m / e=44)$ was measured. In DTA, the temperature difference between the reference and sample crucible, as a result of a thermal event on a sample, is detected as an electrical signal $(\mu \mathrm{V})$. This signal is normalized by software to the sample weight $\left(\mu \mathrm{V} \mathrm{mg}^{-1}\right)$, allowing a direct comparison between different samples. Nonetheless, all measurements were performed on the same amount of the catalyst $(20 \mathrm{mg}$ ) to minimize the influence of additional disturbance variables. Aluminum oxide was chosen as the crucible material because it is inert under the given conditions. An empty crucible of the same size and type was used as reference. Since heat is released during the catalytic oxidation, the DTA signal shows a negative output. For the investigation, the air and methane mixture (1 vol \% $\mathrm{CH}_{4}$ in synthetic air; Air Liquide Deutschland $\mathrm{GmbH}$ ) were automatically switched accordingly to the stated program. The experiments were performed at a constant gas flow rate of $100 \mathrm{~mL} \mathrm{~min}^{-1}$, regulated by mass flow controllers and isothermal conditions within the temperature range of $250<T<450^{\circ} \mathrm{C}$. At each temperature level, the baseline recorded in air was set to zero.

In order to investigate the effect of catalyst particle size, commercially available $\mathrm{Co}_{3} \mathrm{O}_{4}$ powder $(400 \mathrm{mesh} ; 37 \mu \mathrm{m}$; Alfa Aesar; $99.7 \%$ ) was wet ground in a zircon jar by means of a planetary ball mill (PM 100; Retsch $\mathrm{GmbH}$ ) for different durations (between 0.5 and $16 \mathrm{~h}$ ). The samples were

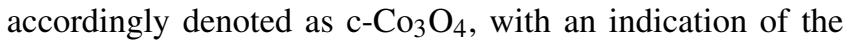
milling duration, e.g., a sample milled for $0.5 \mathrm{~h}$ was named "c- $\mathrm{Co}_{3} \mathrm{O}_{4} \_0.5 \mathrm{~h}$ ". The final samples were first dried at $130^{\circ} \mathrm{C}$ for $3 \mathrm{~h}$ and then thermally treated at $400^{\circ} \mathrm{C}$ for $12 \mathrm{~h}$. Additionally, the $\mathrm{Co}_{3} \mathrm{O}_{4}$ sample was synthesized by the following precipitating procedure: $\mathrm{Co}\left(\mathrm{NO}_{3}\right)_{2} 6 \mathrm{H}_{2} \mathrm{O}(17.46 \mathrm{~g}$; Carl Roth; > $98 \%$ ) was dissolved in $100 \mathrm{~mL}$ deionized water at $23^{\circ} \mathrm{C}$. Then, a KOH solution $\left(1 \mathrm{~mol} \mathrm{~L}^{-1}, 300 \mathrm{~mL}\right)$ was added under the bubbling of nitrogen gas and continuous stirring. A precipitate was collected and washed three times with hot 

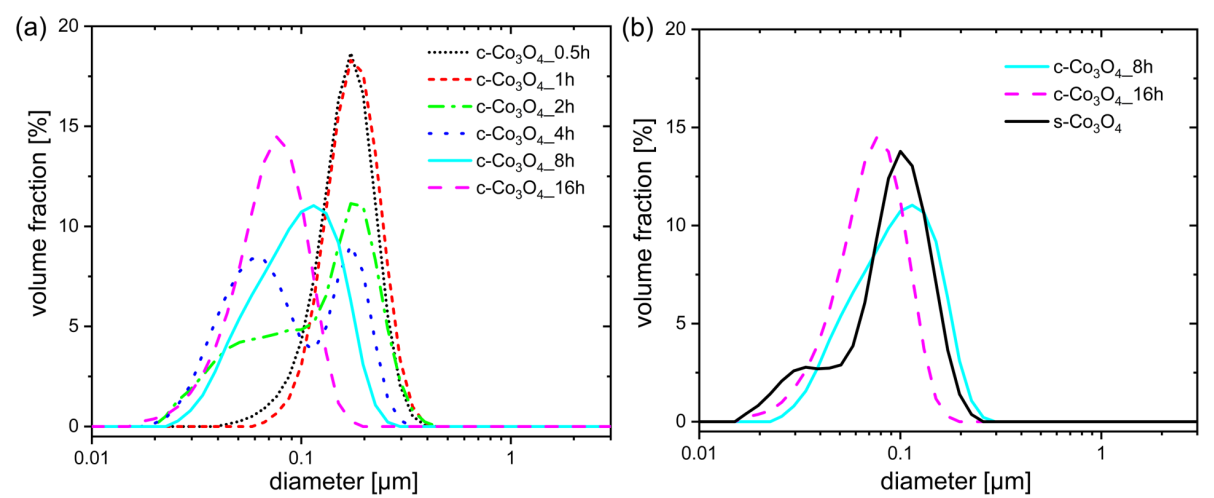

Figure 1. Differential volume distribution of particle sizes obtained for (a) commercial $\mathrm{Co}_{3} \mathrm{O}_{4}$ samples ground for different durations and (b) two $\mathrm{Co}_{3} \mathrm{O}_{4}$ samples ground for 8 and $16 \mathrm{~h}$ in comparison to the synthesized $\mathrm{Co}_{3} \mathrm{O}_{4}$ sample.

deionized water $\left(60^{\circ} \mathrm{C}\right)$, followed by drying at $130^{\circ} \mathrm{C}$ for $24 \mathrm{~h}$. The obtained solid was ground to powder in a mortar and further calcined at $350^{\circ} \mathrm{C}$ in air for $4 \mathrm{~h}$, forming the synthesized catalyst, which was denoted as s- $\mathrm{Co}_{3} \mathrm{O}_{4}$. A detailed description of this procedure can be found elsewhere (Tao et al., 2015).

The particle size distribution was determined with a laser particle size analyzer (LB-550; Horiba Instruments). To determine the particle size distribution, a drop of milled c$\mathrm{Co}_{3} \mathrm{O}_{4}$ samples was dissolved in $10 \mathrm{~mL}$ ethylene glycol. At least five measurements were performed with each sample solution, since the uncertainty of an individual measurement is relatively high, and the mean value was provided for the presentation as result. A scanning electron microscopy (SEM) investigation was performed on a film deposited from sample dispersions after its thermal treatment at $450^{\circ} \mathrm{C}$, using the SU-70 digital elevation model (Hitachi High-Tech Corporation).

For both types of catalysts, a thermal stability test was carried out by alternating between dry synthetic air $(30 \mathrm{~min})$ and the methane mixture atmosphere (volume percentage of $\mathrm{CH}_{4}$ in synthetic air; $30 \mathrm{~min}$ ), firstly at $350^{\circ} \mathrm{C}$ and then at $450{ }^{\circ} \mathrm{C}$, for a total time of $7 \mathrm{~h}$ in each case.

\section{Results}

\subsection{Particle size and morphology of samples}

The $\mathrm{Co}_{3} \mathrm{O}_{4}$ samples were firstly examined with respect to their particle size distribution by means of a particle size analyzer. The particle size is analyzed with regard to a volume distribution representing the population of particles seen by their volume. The volume-average size is more sensitive to the presence of larger particles. It should be noted that this analysis technique does not provide any information about particle shapes and is more accurate for determining the representative diameter of relatively spherical particles (Burgess et al., 2004). To manufacture the samples with a controlled reduction in particle size, the commercial micro-sized $\mathrm{Co}_{3} \mathrm{O}_{4}$

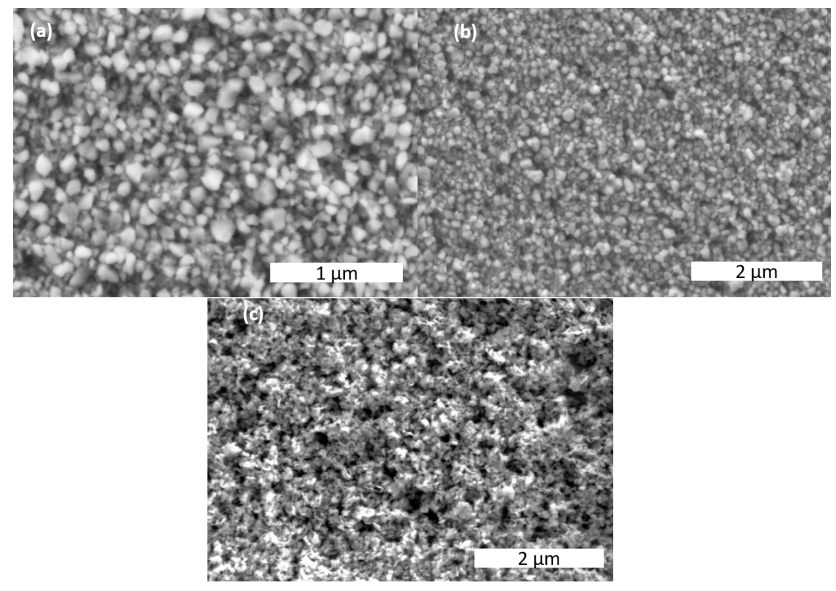

Figure 2. $\mathrm{SEM}$ images of $(\mathbf{a}, \mathbf{b})$ commercial $\mathrm{Co}_{3} \mathrm{O}_{4}$ nano powder, after milling for $8 \mathrm{~h}\left(\mathrm{c}-\mathrm{Co}_{3} \mathrm{O}_{4} \_8 \mathrm{~h}\right)$ in different magnifications, and (c) synthesized $\mathrm{Co}_{3} \mathrm{O}_{4}\left(\mathrm{~s}-\mathrm{Co}_{3} \mathrm{O}_{4}\right)$.

powder was milled for defined durations. For comparison, a $\mathrm{Co}_{3} \mathrm{O}_{4}$ sample with initially nano-sized particles was synthesized by the precipitation method.

The investigation of the particle size distributions of ground samples (Fig. 1a) exhibits that, after milling for $30 \mathrm{~min}$ and $1 \mathrm{~h}\left(\mathrm{c}_{-} \mathrm{Co}_{3} \mathrm{O}_{4}{ }_{-} 0.5 \mathrm{~h}\right.$ and $\left.\mathrm{c}-\mathrm{Co}_{3} \mathrm{O}_{4} \_1 \mathrm{~h}\right)$, the majority of the total particle volume originates from particles with sizes between 100 and $400 \mathrm{~nm}$, exhibiting a peak at ca. $200 \mathrm{~nm}$. With a continuous increase in the milling time, a second peak appears at lower particle sizes $\left(\mathrm{c}^{-} \mathrm{Co}_{3} \mathrm{O}_{4} \_2 \mathrm{~h}\right.$; $\left.\mathrm{c}-\mathrm{Co}_{3} \mathrm{O}_{4} 4 \mathrm{~h}\right)$ and rises over time until the first peak disap-

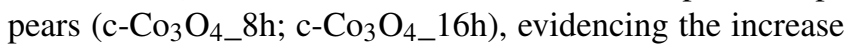
in the volume percentage of small particles. In comparison to $\mathrm{Co}_{3} \mathrm{O}_{4}$ samples ground for 8 and $16 \mathrm{~h}$, represented by curves with single maximum at 100 and $80 \mathrm{~nm}$, the synthesized one $\left(\mathrm{s}-\mathrm{Co}_{3} \mathrm{O}_{4}\right)$ exhibits a broad curve with two maxima located at 100 and $30 \mathrm{~nm}$, respectively (Fig. 1b). The maximum at $30 \mathrm{~nm}$ evidences the presence of smaller particles for the synthesized $\mathrm{Co}_{3} \mathrm{O}_{4}$ sample in a high amount. 

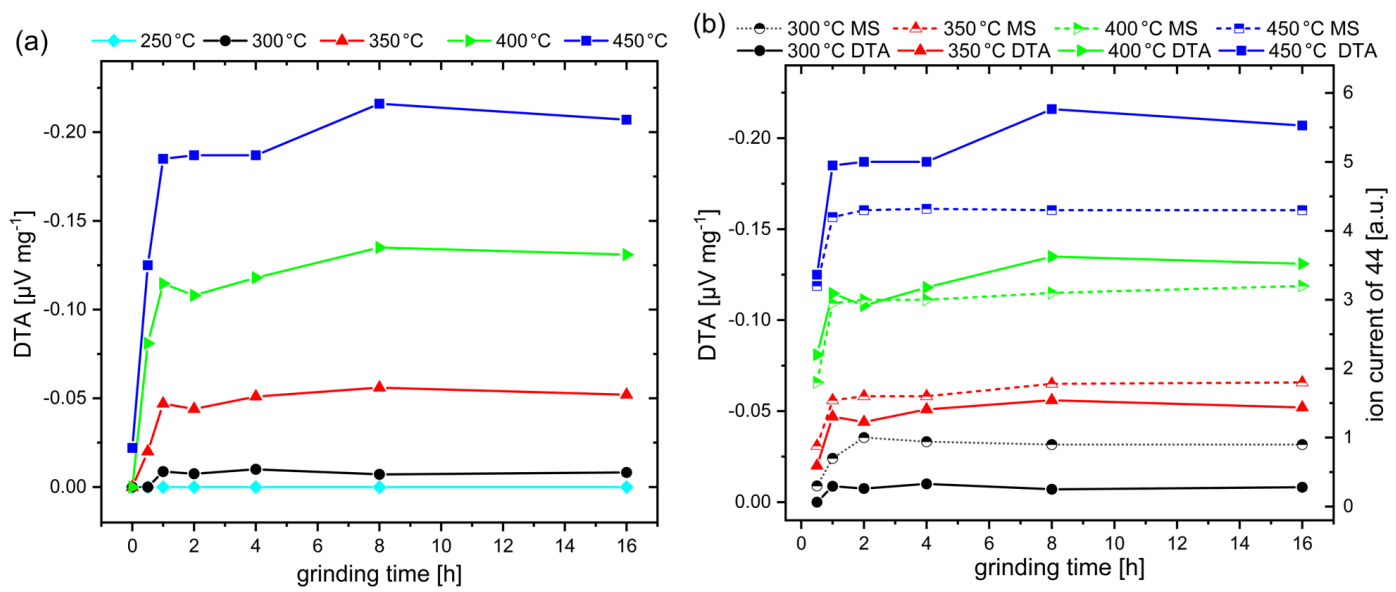

Figure 3. (a) DTA response obtained on $\mathrm{CH}_{4}$ exposure ( $1 \mathrm{vol} \%$ in dry air) of commercial $\mathrm{Co}_{3} \mathrm{O}_{4}$ catalysts as a function of grinding time and operating temperature. (b) DTA response in comparison to MS response obtained by simultaneous measurements.

SEM images of $\mathrm{Co}_{3} \mathrm{O}_{4}$ milled for $8 \mathrm{~h}$ (Fig. $2 \mathrm{a}$ and $\mathrm{b}$ ) affirm that particles of different sizes are present in the sample. In addition, as an imaging technique, SEM reveals the presence of spherical particles with sharp edges, which is expected for the mechanical breaking of big particles. The particles also form a compact layer. These SEM investigations on the synthesized sample (Fig. 2c) indicated that the particles are not spherical and possess a rather random shape. Additionally, most particles reveal a rather flat shape, which is a significant difference to the milled $\mathrm{Co}_{3} \mathrm{O}_{4}$ samples.

\subsection{Effect of grain size and morphology on thermal response}

Figure 3a illustrates the dependence of the DTA response to commercial $\mathrm{Co}_{3} \mathrm{O}_{4}$ on the grinding time in a temperature range between 250 and $450^{\circ} \mathrm{C}$, since high temperatures of up to $450^{\circ} \mathrm{C}$ are usually used for the pellistor operation. The original $\mathrm{Co}_{3} \mathrm{O}_{4}$ powder with micro-sized particles exhibits no DTA response to methane up to $400{ }^{\circ} \mathrm{C}$. First, at $450{ }^{\circ} \mathrm{C}$, a minor signal of $-0.022 \mu \mathrm{V} \mathrm{mg}^{-1}$ is observed. Indeed, increasing the grinding time leads to a successive increase in the DTA response at temperatures starting from $300^{\circ} \mathrm{C}$, which is especially noticeable in the first $2 \mathrm{~h}$ of grinding. A further increase in the grinding time has no significant effect on improving the catalytic activity. The initial response increase correlates well with reduction in the particle size, as indicated by particle size investigations (Fig. 1a), which should be a result of the increased surface area accessible for gas contact and reaction. The minor increase in the thermal response by the further decrease in particle size can be explained by the particle packing density in the sample powder. With progressive grinding time and an increase in the polydispersity of the system, the packing density of the spherical particles should increase, since small particles can efficiently occupy the voids created by neighboring large parti- cles (Desmond and Weeks, 2014; Elmsahli and Sinka, 2020). The reduction in the particle size increases the cohesion between the particles, which, furthermore, affects the density of the samples (Elmsahli and Sinka, 2020). The porosity decrease, as a result of attractive forces between nano-sized particles, is a possible explanation for the minor effect of continued milling on the DTA response, which counteracts the positive effect of an increased particle surface.

When the DTA signal (solid line) is compared with the MS signal (dashed line) (Fig. 3b; the results for non-milled $\mathrm{Co}_{3} \mathrm{O}_{4}$ sample and for $250^{\circ} \mathrm{C}$ are not included), it is obvious that the grinding time dependence of the MS signal follows the dependence on the DTA signal but with an offset. A significant MS signal can already be observed at $300^{\circ} \mathrm{C}$, while the DTA signal is still minor. Moreover, the difference in the signal height of the MS and DTA signal becomes smaller with increasing operating temperature and is reversed at $400{ }^{\circ} \mathrm{C}$. In relative terms, the DTA signal is higher than the MS signal at 400 and $450^{\circ} \mathrm{C}$. Figure $4 \mathrm{a}$ shows the different developments of the DTA (lower half of graph) and the MS curve (upper half of graph) with the example of a $\mathrm{Co}_{3} \mathrm{O}_{4}$ sample ground for $8 \mathrm{~h}$. The MS signal already appears at $250^{\circ} \mathrm{C}$, while no thermal signal is observed. This deviation can be explained by the fact that some amount of heat evolved by the reaction is required to heat the crucible before the temperature increase can be detected by thermocouples. The deviations in the responses result from the specifics of both methods.

The comparison of the DTA curves of commercial $\mathrm{Co}_{3} \mathrm{O}_{4}$ ground for $8 \mathrm{~h}$ with one of the prepared $\mathrm{Co}_{3} \mathrm{O}_{4}$ (Fig. $4 \mathrm{~b}$ ) reveals that synthesized $\mathrm{Co}_{3} \mathrm{O}_{4}$, with initially nano-sized particles and a random shape, shows considerably higher activity (black line). At $350^{\circ} \mathrm{C}$, the DTA response of synthesized $\mathrm{Co}_{3} \mathrm{O}_{4}$ is three times higher compared to ground $\mathrm{Co}_{3} \mathrm{O}_{4}$, with $-0.18 \mu \mathrm{V} \mathrm{mg}^{-1}$ vs. $-0.06 \mu \mathrm{V} \mathrm{mg}^{-1}$, respectively, while, at $450^{\circ} \mathrm{C}$, the DTA signal ratio is only 1.3 for both catalysts. 

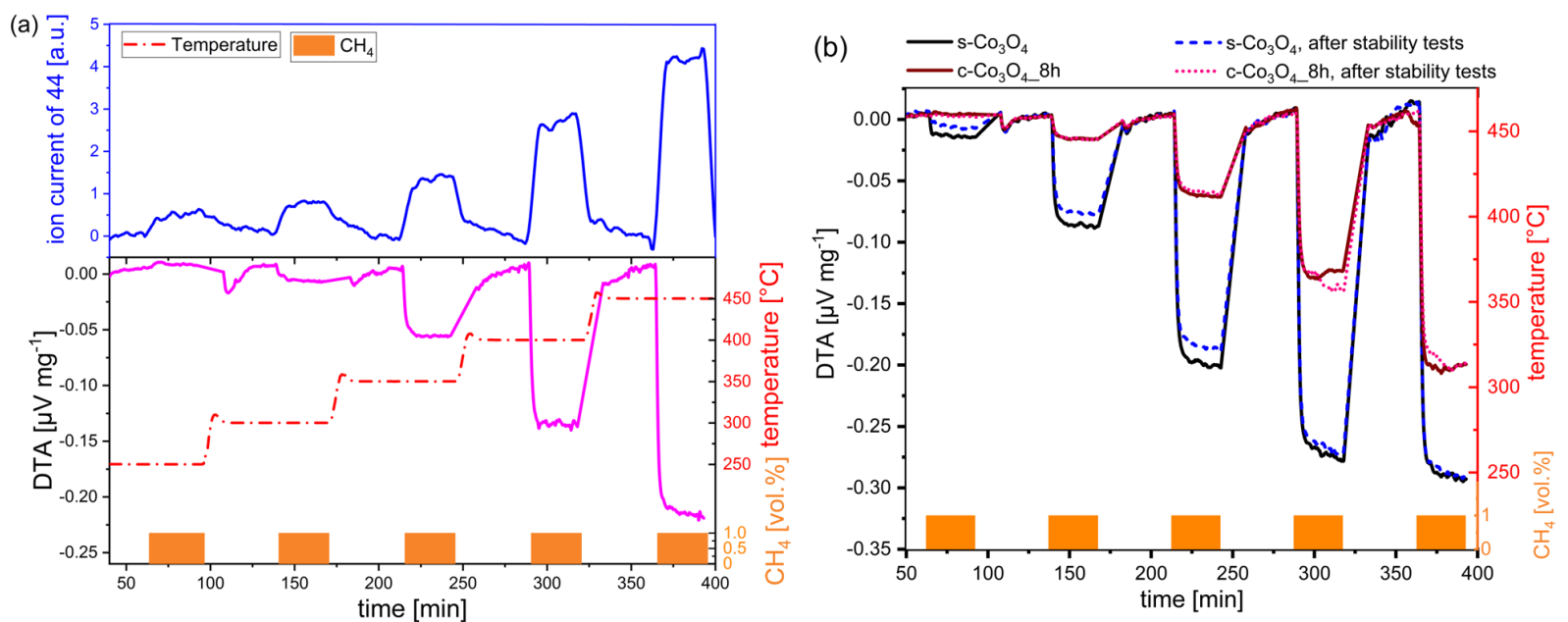

Figure 4. (a) DTA curve in comparison to MS curve of ground $\mathrm{Co}_{3} \mathrm{O}_{4}(8 \mathrm{~h})$ under exposure to $\mathrm{CH}_{4}$. (b) DTA curves for two different $\mathrm{Co}_{3} \mathrm{O}_{4}$ catalysts before and after thermal stability investigations. Conditions - pulses of 1 vol $\% \mathrm{CH}_{4}$ in dry air for 30 min in a temperature range between 250 and $450{ }^{\circ} \mathrm{C}$.

This points out that, at high operating temperatures, the advantage of a catalyst with high catalytic activity is less pronounced than at low operating temperatures.

The considerably higher activity of synthesized $\mathrm{Co}_{3} \mathrm{O}_{4}$ can be explained, on the one hand, by its lower particle size (Fig. 1b) and, on the other hand, by differences in the morphology of both samples, since the particle shape is a further key factor affecting the packing of the material and its porosity. Irregularities in the particle shape influence the interparticle friction, lowering the packing density (Elmsahli and Sinka, 2020). The irregular particles can be assembled in a less dense configuration, with higher porosity and bigger surface area accessible for gas interactions. Future investigations should clarify to what extent the particle shape has an influence on DTA response.

The results of the thermal stability test are shown for both types of catalysts in Fig. 4b. Synthesized $\mathrm{Co}_{3} \mathrm{O}_{4}$ exhibits a slightly lower thermal stability than the commercial one. The decrease in activity after thermal treatment in a methanecontaining atmosphere is particularly observed at lower operating temperatures $\left(\leq 350^{\circ} \mathrm{C}\right)$, which are more interesting for pellistor applications. The reason for the decreased activity of synthesized $\mathrm{Co}_{3} \mathrm{O}_{4}$ originates most probably from its loosely packed morphology and the sintering of nanoparticles occurring at high operating temperatures $\left(450^{\circ} \mathrm{C}\right)$. In addition, small particles are more susceptible to sintering than large particles (Hakvoort and Xiaoding, 1991).

\section{Conclusion}

Differential thermal analysis (DTA) was used to examine the effect of the morphology of $\mathrm{Co}_{3} \mathrm{O}_{4}$ catalysts on the thermal response towards methane gas with regard to pellistor applications. The evaluation was performed by means of ground and synthesized $\mathrm{Co}_{3} \mathrm{O}_{4}$ catalysts. It has been demonstrated that, in addition to particle size, the particle shape also plays an essential role in determining the thermal response by influencing the packing of the particles in the layer and, therefore, the surface area of the catalyst. The initially nano-sized $\mathrm{Co}_{3} \mathrm{O}_{4}$ sample with an irregular shape of nanoparticles had a considerably higher thermal response than ground samples with approximately spherical particles and an increased tendency to form compact layers. Consequently, the investigations demonstrate the limits of the milling method for increasing the surface area and improving the sensor sensitivity. Furthermore, the morphology of $\mathrm{Co}_{3} \mathrm{O}_{4}$ catalysts had a higher impact on the improvement of the response than raising the temperature. Nevertheless, the effect of the catalyst activity was less pronounced at $450^{\circ} \mathrm{C}$ than at $350^{\circ} \mathrm{C}$, which is the most interesting temperature for pellistor applications. The thermal stability of nano-sized $\mathrm{Co}_{3} \mathrm{O}_{4}$ particles, as determined after successive measurements at $450{ }^{\circ} \mathrm{C}$, is slightly lower due to the sintering process occurring. The influence of the morphological parameters should be investigated in more detail in further work. Finally, the thermal response from the DTA was compared with the signal of evolved carbon dioxide as an oxidation product by means of mass spectrometry (MS), which was integrated into a measurement system. The deviation of the signals detected by DTA and MS was explained by the principle of the thermal method.

Data availability. All relevant data presented in the article are stored in a public data repository, Fordatis, under https://doi.org/10.24406/fordatis/118 (Yurchenko et al., 2021). 
Author contributions. JW created the concept for pellistor development and was responsible for the funding acquisition. LE prepared the $\mathrm{Co}_{3} \mathrm{O}_{4}$ samples from commercial metal oxide and conducted the particle size examinations. OY carried out the synthesis of $\mathrm{Co}_{3} \mathrm{O}_{4}$ sample, performed the SEM and DTA investigations and wrote the original draft. The concept of DTA method as a tool for catalyst screening was developed by OY and HFP in close discussion with JW, MJ and BB. HFP was responsible for the DTA measurement instrumentation. All authors contributed to the reviewing and editing of the final paper.

Competing interests. The authors declare that they have no conflict of interest.

Special issue statement. This article is part of the special issue "Sensors and Measurement Science International SMSI 2020". It is a result of the Sensor and Measurement Science International, Nuremberg, Germany, 22-25 June 2020.

Acknowledgements. This work was supported by the Fraunhofer Society as part of the FluMEMs research project and also the Sustainability Center Freiburg as part of the LeakAlert project.

Financial support. This research has been supported by the Fraunhofer Society (grant FluMEMS).

Review statement. This paper was edited by Jens Zosel and reviewed by two anonymous referees.

\section{References}

Beecroft, T., Miller, A. W., and Ross, J. R. H.: The use of differential scanning calorimetry in catalyst studies. The methanation of carbon monoxide over nickel/alumina catalysts, J. Catal., 40, 281-285, https://doi.org/10.1016/0021-9517(75)90255-9, 1975.

Borchardt, H. J. and Daniels, F.: The Application of Differential Thermal Analysis to the Study of Reaction Kinetics, J. Am. Chem. Soc., 79, 41-46, https://doi.org/10.1021/ja01558a009, 1957.

Burgess, D. J., Duffy, E., Etzler, F., and Hickey, A. J.: Particle size analysis: AAPS workshop report, cosponsored by the Food and Drug Administration and the United States Pharmacopeia, AAPS J., 6, 20, https://doi.org/10.1208/aapsj060320, 2004.

Chen, J., Arandiyan, H., Gao, X., and Li, J.: Recent Advances in Catalysts for Methane Combustion, Catal. Surv. Asia, 19, 140171, https://doi.org/10.1007/s10563-015-9191-5, 2015.

Chen, Z., Wang, S., Liu, W., Gao, X., Gao, D., Wang, M., and Wang, S.: Morphology-dependent performance of $\mathrm{Co}_{3} \mathrm{O}_{4}$ via facile and controllable synthesis for methane combustion, Appl. Catal. A, 525, 94-102, https://doi.org/10.1016/j.apcata.2016.07.009, 2016.
Desmond, K. W. and Weeks, E. R.: Influence of particle size distribution on random close packing of spheres, Phys. Rev. E, 90, 22204, https://doi.org/10.1103/PhysRevE.90.022204, 2014.

Elmsahli, H. S. and Sinka, I. C.: A discrete element study of the effect of particle shape on packing density of fine and cohesive powders, Comp. Part. Mech., 20, 155, https://doi.org/10.1007/s40571-020-00322-9, 2020.

Grisel, R. J. H., Kooyman, P. J., and Nieuwenhuys, B. E.: Influence of the Preparation of $\mathrm{Au} / \mathrm{Al}_{2} \mathrm{O}_{3}$ on $\mathrm{CH}_{4}$ Oxidation Activity, J. Catal., 191, 430-437, https://doi.org/10.1006/jcat.1999.2787, 2000.

Hakvoort, G.: Measurement of heterogeneously catalyzed gas reactions by DSC, J. Therm. Anal., 47, 445-452, https://doi.org/10.1007/BF01983986, 1996.

Hakvoort, G. and Xiaoding, X.: Decomposition of methanol vapour over solid catalyst, measured by DSC, J. Therm. Anal., 37, 12691279, https://doi.org/10.1007/BF01913860, 1991.

Janssen, F.: The use of thermal analysis techniques in heterogeneous catalysis, Thermochim. Acta, 148, 137-147, https://doi.org/10.1016/0040-6031(89)85210-4, 1989.

Le Parlouër, P.: Thermal Analysis and Calorimetry Techniques for Catalytic Investigations, in: Calorimetry and Thermal Methods in Catalysis, vol. 154, edited by: Auroux, A., 52 pp., Springer, Berlin, Heidelberg, https://doi.org/10.1007/978-3-64211954-5_2, 2013.

Loskyll, J., Maier, W. F., and Stoewe, K.: Application of a Simultaneous TGA-DSC Thermal Analysis System for HighThroughput Screening of Catalytic Activity, ACS Comb. Sci., 14, 600-604, https://doi.org/10.1021/co3000659, 2012.

Pu, Z., Zhou, H., Zheng, Y., Huang, W., and Li, X.: Enhanced methane combustion over $\mathrm{Co}_{3} \mathrm{O}_{4}$ catalysts prepared by a facile precipitation method: Effect of aging time, Appl. Surf. Sci., 410, 14-21, https://doi.org/10.1016/j.apsusc.2017.02.186, 2017.

Stakheev, A. Y., Batkin, A. M., Teleguina, N. S., Bragina, G. O., Zaikovsky, V. I., Prosvirin, I. P., Khudorozhkov, A. K., and Bukhtiyarov, V. I.: Particle Size Effect on $\mathrm{CH}_{4}$ Oxidation Over Noble Metals: Comparison of Pt and Pd Catalysts, Top. Catal., 56, 306-310, https://doi.org/10.1007/s11244-013-9971-y, 2013.

Tao, F. F., Shan, J.-J., Nguyen, L., Wang, Z., Zhang, S., Zhang, L., Wu, Z., Huang, W., Zeng, S., and Hu, P.: Understanding complete oxidation of methane on spinel oxides at a molecular level, Nat. Commun., 6, 65, https://doi.org/10.1038/ncomms8798, 2015.

Trautweiler, S., Moser, N., Delprat, H., Lepoutre, S., Alépée, C., Brown, T., and Brown, K.: Disruptive MEMS Technology Replaces Conventional Bead Pellistor Device, in: IMCS 2012, 20 May 2012, Nuremberg, Germany, https://doi.org/10.5162/IMCS2012/3.4.3, 2012.

White, R.: The pellistor is dead? Long live the pellistor! 2014, available at: https://www.envirotech-online. com/article/environmental-laboratory/7/sgx-sensortech/ the-pellistor-is-dead-nbsplong-live-the-pellistor/1699 (last access: 26 January 2021), 2014.

Yurchenko, O., Engel, L., and Pernau, H.-F.: Impact of particle size and morphology of cobalt oxide on thermal response to methane examined by thermal analysis, fordatis, https://doi.org/10.24406/fordatis/118, 2021. 